Am. J. Trop. Med. Hyg., 71(Suppl 2), 2004, pp. 224-231

Copyright (C) 2004 by The American Society of Tropical Medicine and Hygiene

\title{
MONITORING FUTURE IMPACT ON MALARIA BURDEN IN SUB-SAHARAN AFRICA
}

\author{
DON DE SAVIGNY AND FRED BINKA \\ International Development Research Centre, Ottawa, Ontario, Canada; INDEPTH Network, Accra, Ghana
}

\begin{abstract}
Ambitious new goals for control of malaria have been set and significant additional resources for malaria control are being mobilized. Yet for many of the countries most severely burdened by malaria, both baseline data and reliable monitoring of key impact indicators is lacking. For such countries, it will be difficult to know when targets are met or whether to make mid-course corrections if progress is inadequate. The new investments in malaria control have triggered resurgence in demand for health information, both for performance-based resource allocation and for health impact. We argue here that some of these resources will need to be diverted to support more integrated information systems able to monitor change and guide approaches, not just for malaria, but also for other important health and poverty related interventions. This paper urges a re-thinking of the nature of management information systems and sources in resource poor settings. A pathway is suggested that helps situate monitoring and evaluation more strategically in a framework of other information management steps for longitudinal, iterative, evidence-based decision making. Health Information Systems of the future will need much greater coherence in the use of information from disparate sources and much greater influence on action.
\end{abstract}

\section{FINAGLE'S THREE LAWS OF INFORMATION}

"The data we have are not the data we want."

"The data we want are not the data we need."

"The data we need are not available."

\section{INTRODUCTION}

In this report, we reflect on the various means currently available for monitoring progress in malaria control. We provide a framework for thinking about the supply side of information for malaria control that should help guide choices for how to monitor the impact of new resources now becoming available for malaria control. We also provide a pathway for helping data have a greater influence on action. Terms such as monitoring, evaluation, and forecasting for malaria control suggest a focus on evidence-based decision making for malaria control. Progress at the pace required will need strategies, plans, priority setting, resource allocation, and action that are rooted in contemporary empirical data for timely and meaningful indicators of progress. Yet there is often confusion in the use of terms such as data, information, monitoring, evaluation, and forecasting, and how these conceptually fit together in management information systems. Clearer understanding should allow a more strategic overall effort to embed malaria control and prevention more firmly in health systems, and in the daily realities of those at risk.

\section{NEW GOALS}

We need no reminding that the problem of malaria in Africa is immense. The meager but growing resources to deal with it will always be inadequate. To succeed, strategies, plans, and decisions for how scarce resources are allocated and choices are made, whether at the family and household level or at the system and policy level, will need to be very smart indeed. And that means they will need to be very well informed. This is all the more important given the new targets and resources for malaria control that are framed in the ambitious Millennium Development Goals (MDGs) ${ }^{1}$ and more specifically, the Roll Back Malaria $(\mathrm{RBM})^{2}$ and Abuja targets. $^{3}$ The MDGs for 2015 address poverty, hunger, primary education, sex equity, under-five and maternal mortality, safe water, environmental sustainability, and global partnerships for development. Progress on any of these fronts will be good for malaria control in Africa. The MDGs also make specific mention of arresting human immunodeficiency virus/acquired immunodeficiency syndrome (HIV/AIDS) and malaria. One of the more instructive indicators for malaria in sub-Saharan Africa is all-cause child mortality. Here the MDG target is to reduce under-five mortality by two-thirds between 1990 and 2015 , which is about a $4 \%$ reduction per year compounding over each of these 25 years. The targets look attainable in most regions except sub-Saharan Africa where the situation appears bleak. Decreases in child mortality in the decades prior to the 1990s were on this trajectory, but during the 1990s there was stagnation, and in some places, reversal of the trends. ${ }^{4}$ Across sub-Saharan Africa, average under-five mortality decreased a total of only $3 \%$ during the entire decade of the 1990s, while during the same period in industrialized countries, the already low mortality decreased an additional $32 \%$, putting them well on the road to meeting $\mathrm{MDGs}^{5}$ (Figure 1$)$.

Why is Africa having such trouble moving toward these goals? One reason must be the failure to control malaria. Malaria constitutes $23-37 \%$ of child deaths in sub-Saharan Africa. ${ }^{6}$ It will be difficult to cut under-five mortality by twothirds without making major progress on malaria control because it is the largest disease component of the burden. This, plus the strong association of malaria with maternal mortality and with poverty ${ }^{7}$ suggests that progress on those Millennium indicators will also be hampered by a failure to substantially reduce malaria. Failure to reduce the intolerable economic and disease burden of malaria will seriously undermine prospects to achieve MDGs in Africa.

A huge effort and investment on malaria is clearly required. It is therefore quite extraordinary that the MDG specific for malaria is so feeble. It calls only for a halt in the growing incidence of malaria by 2015 and a reversal thereafter. If malaria is held at the current incidence, Africa is doomed to carry the current burden of malaria until 2015 and the Millennium goals will be impossible to reach. There seems to be an internal contradiction in the Millennium Goals when it comes to appreciating the pivotal importance of malaria in 


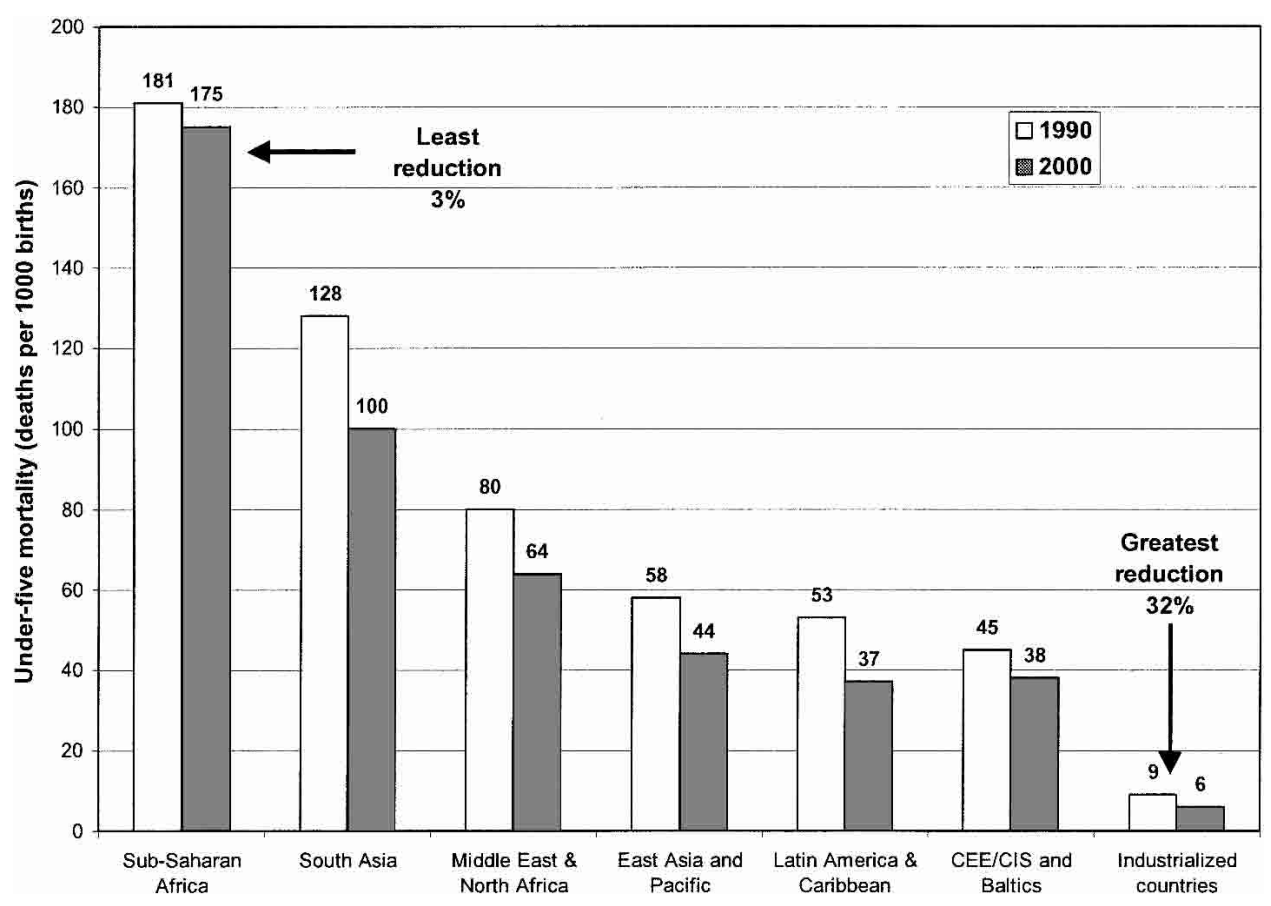

FIGURE 1. Under five mortality reductions by region between 1990 and 2000. CEE/CIS = Central and Eastern Europe/Commonwealth of Independent States. Adapted from United Nations Children's Fund http://www.unicef.org/specialsession/about/sgreport-pdf/01_ InfantAndUnder-FiveMortality_D7341Insert_English.pdf (accessed January 9, 2004).

sub-Saharan Africa. Not just a simple arrest, but also an actual reduction of the malaria burden is urgently required. The RBM and Abuja targets are more incisive. The RBM target is to halve the 1990 malaria morbidity and mortality by the year $2010 .^{2}$ To achieve this, at Abuja African heads of state resolved to strengthen national health systems to ensure that by the year $200560 \%$ of malaria patients will have access to appropriate treatment within 24 hours of onset of symptoms; $60 \%$ of children and pregnant women at risk of malaria will be protected using insecticide-treated nets (ITNs); $60 \%$ of pregnant women will have access to appropriate malaria chemoprophylaxis or presumptive intermittent treatment; and $60 \%$ of epidemics will be detected within two weeks of onset, and responded to within two weeks of detection. Interventions capable of reaching the targeted mortality reductions are already available. Insecticide-treated nets alone can be expected to reduce malaria morbidity by $50 \%$ and allcause under five mortality by $17 \%{ }^{8}$ This, coupled with a move away from failing first-line antimalarials in primary care, plus new interventions in the pipeline such as intermittent presumptive treatment of infants (IPTi) ${ }^{9}$ and new strategies to reach children with higher quality interventions such as Integrated Management of Childhood Illnesses ${ }^{10}$ auger well. If successful, then the MDGs for Africa will come back within reach. The weak point is systemic rather than technical. Reaching the Millennium Goals will require enhanced capacities and commitments across a number of fronts, particularly human resources development, financial investments, and system-wide initiatives to increase the reach, coverage and equity of essential services. The World Bank estimates a need for \$40-60 billion U.S. dollars per year in additional annual funding for the MDGs. ${ }^{11}$ The World Health Organization (WHO) estimates a need for $\$ 1$ billion U.S. dollars per year to reach Abuja malaria control targets, while current spending is about 200 million per year. ${ }^{12}$ Even with new resources such as debt relief and the Global Fund for AIDS, tuberculosis, and malaria, it will be unlikely that this level of investment can be mobilized and spent quickly, so whatever is obtained will need to be used very carefully and its impact monitored.

\section{A PATHWAY TO EVIDENCE-BASED PLANNING}

To guide and evaluate these investments, it is logical that some of the new funding (perhaps 5-7\%) must be invested in information systems. Such systems are particularly weak and inadequate in sub-Saharan Africa. The new goals and investments provide an opportunity to re-engineer currently weak management information systems; to build them to serve more than just single disease, or even single sector interests, yet still provide what is needed.

One of the reasons the information systems are weak is that monitoring and evaluation is not treated as a coherent element in a routine pathway to evidence-based decisionmaking. Such a pathway starts with data, the minimum for process and impact indicators required to track and guide progress. What data, and how it is obtained is crucial and discussed later. However, data, alone, are useless until cleaned, controlled, organized, analyzed, and integrated with other data to become elevated to the status of information. Once data becomes information, this is usually where the whole process stops. However, information on its own is useless until it becomes evidence of something. Making information "speak" requires a set of skills and tools to transform and package it to reveal the evidence it embodies. Once information is distilled to evidence, it must move on because evidence is of little value until communicated to the "movers and shak- 
ers"; the policy makers, politicians, program managers, planners, decision makers, the public, the mothers, or whoever needs to know. Once this happens, evidence transforms to new knowledge; a new understanding about what is important to do next. However, knowledge in turn is useless until applied to influence action through decisions and plans that are implemented. Action is the purpose of any information system and is essential for achieving impact or change. When things change, the data change. And it is in such a loop that the monitoring, evaluation, and forecasting of our indicators comes into play and feeds the cycle as a new source of data. This is essentially a pathway for evidence-based planning in which monitoring, evaluation, and forecasting are essential but insufficient steps (Figure 2). It looks obvious, but too often, important data fail to have the influence it should because this pathway is so frequently short-circuited. Going directly from information to policy makers or implementers often fails. There are many examples of interventions that should have been adopted much earlier than they were, policies that should have been changed sooner, and epidemics that deserved swifter responses. Often the data and even the information are available but its proper packaging, communication, and follow through are neglected. If this loop is not closed, the management information system, as a system, is incomplete (Figure 2).

\section{A FRAMEWORK FOR MALARIA INDICATORS}

The above pathway to action is predicated on data for key indicators necessary to guide the health system being available from within a coherent Health Information System. For malaria, RBM has prepared a framework of data sources and indicators for monitoring and evaluating malaria control that are selected on principles of broad consensus, relevance to the RBM goals, standardized but adaptable approaches to collection, local feedback to the system, and minimal data collection. ${ }^{13}$ This last point is important. Roll Back Malaria has fought against what has been called the "epidemic of

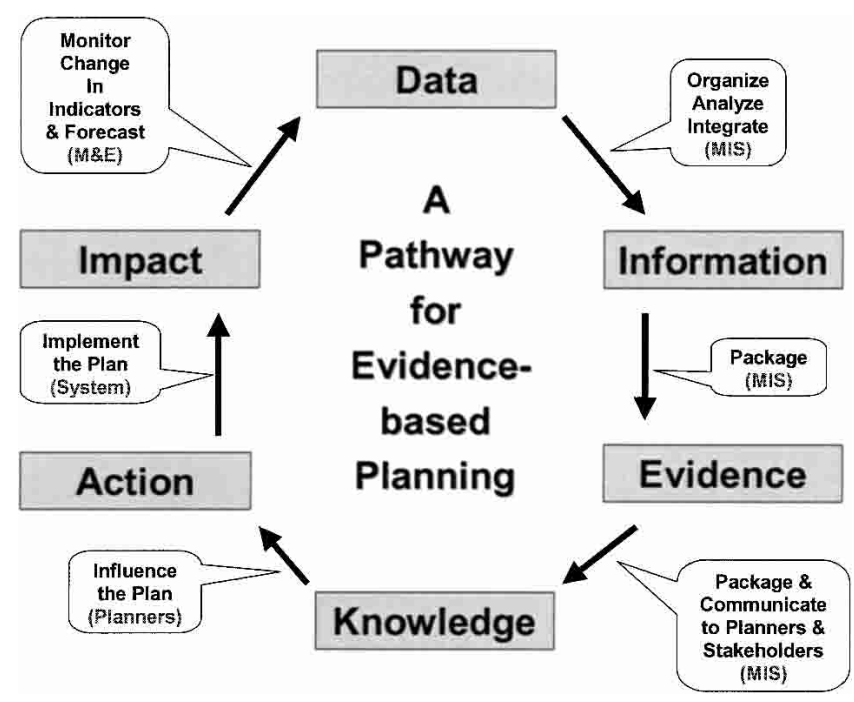

FIGURE 2. A pathway for evidence-based planning. $\mathrm{M} \& \mathrm{E}=$ monitoring and evaluation; MIS = management of information system. indicators" (Boerma JT, unpublished data) demanded by disease control programs and identifies less than two dozen indicators of interest to malaria control in endemic countries, of which only about half are essential. Of those that are essential, nine are at household or population level and thus more difficult for the health system to capture. However, it is these household level indicators that are key to knowing if mortality and morbidity are being reduced. They must be measured at household level now and prospectively into the future along with health system process indicators for the strategies. The RBM has provided a thorough description of these indicators. ${ }^{14}$ It is straightforward on the surface but how to get these basic process and impact data is a more difficult question.

\section{DATA SOURCES FOR MONITORING MALARIA CONTROL}

For malaria control, data can come from three main levels: the Health Facility/Health System Level, the Community/ Household Level, and the Remote Sensing and Modeling level. Each of these levels can provide data prospectively or retrospectively (Table 1 ).

\section{HEALTH FACILITY DATA}

Starting at the Health Facility Level, there is continuous prospective surveillance producing the kind of data routinely collected in health facilities by conventional Health Management Information Systems (HMIS) or Integrated Disease Surveillance (IDS). There are also periodic cross-sectional retrospective surveys such as the IMCI evaluation or similar facility-based surveys. It is to these sources that disease control managers and health system planners look most frequently as an evidence source. However, it is seldom appreciated that data derived from the health facility level are inherently flawed and biased when used to monitor key indicators for population level burdens of disease or health seeking behaviors. Health facility data is a good example of Finagle's first law. It is the data we have, but not necessarily the data we want, nor the data we need. The HMIS data would be better reserved for managing health facilities. For example, health planners need to know about intervention costs, coverage, and provider compliance, but they can rarely find such information in their HMIS indicators and data sets.

\section{TABLE 1}

Types and levels of data sources for health information systems important for malaria control programs*

\begin{tabular}{lll}
\hline & \multicolumn{2}{c}{ Type } \\
\cline { 2 - 3 } Level & Cross-sectional retrospective & Longitudinal prospective \\
\hline $\begin{array}{c}\text { Individual and } \\
\text { household }\end{array}$ & $\begin{array}{c}\text { Population surveys } \\
\text { (Census, DHS, MICS) }\end{array}$ & $\begin{array}{c}\text { Prospective surveillance } \\
\text { (Vital events and } \\
\text { DSS) }\end{array}$ \\
Health facility & $\begin{array}{c}\text { Routine reporting } \\
\text { (HMIS, IDS, DHS) }\end{array}$ & $\begin{array}{c}\text { HF surveys } \\
\text { Modeling }\end{array}$ \\
$\begin{array}{c}\text { Risk mapping (GIS) } \\
\text { Remote sensing and } \\
\text { early warning systems }\end{array}$ \\
\hline
\end{tabular}

$*$ DHS $=$ Demographic and Health Survey; MICS = Multi-indicator Cluster Survey; DSS $=$ Demographic Surveillance System; HMIS $=$ Health Management Information System IDS = Integrated Disease Surveillance; HF = health facility; GIS = geographic information system. 
Instead, most efforts of HMIS are directed at attendance data that is then used as a proxy for population health, as if the problems of the population attending health services are representative of the health problems of those who do not attend. However, most deaths in Africa occur at home, and many without any health-seeking behavior at formal health services monitored by HMIS. The proportion of febrile children less than five years old who are treated with antimalarials ranges from approximately $2.5 \%$ to a maximum of $65 \%$ in subSaharan Africa. ${ }^{12}$ People may be differentially deflected or repelled from these services by a whole range of issues including geographic and physical access, socioeconomic access, temporal access, sex, age, belief systems, quality of health services, and availability of drugs. Yet it is extraordinary how much time, energy, resources, and opportunity costs are spent collecting and processing health facility attendance data to monitor disease. Conclusions can be fallacious. In a health system under reform that is achieving necessary improvements in quality of services or in completeness of record keeping and reporting, one can expect to see marked increases in attendance. Does this mean that the disease trend is increasing? More likely it is the opposite. The only way to know is to go to the household level. This is not to say that facility data on disease statistics are without value. Where they have been most valuable is with regard to understanding health system performance for severe disease (case fatality rates for in-patients for example) where the population of interest is those who do arrive.

\section{HOUSEHOLD DATA}

The most important level to measure impact is at the household and community level where again, data can be obtained prospectively from continuous surveillance such as sample registration or sentinel demographic surveillance systems (DSS) (http://indepth-network.net), or retrospectively from periodic, cross-sectional national household surveys such as Demographic and Health Surveys (DHS) (http:// www.measuredhs.com) or Multiple Indicator Cluster Surveys (MICS) (http://www.unicef.org/reseval/micsr.html). These approaches have either total sampling or very carefully constructed representative sampling methods that avoid the selfselection bias seen in the HMIS and IDS data.

The DSS sites monitor large populations continuously (typically at least 60,000 people per site), with full vital event registration in what are essentially sample or sentinel populations that is conducted and updated between one and four times per year, including cause of death ascertainment by verbal autopsy for all deaths. Because of the repeated household surveillance approach, over time, geo-referenced contextual data on socioeconomic, environmental, and health system access variables can also be linked with each individual in the population. Almost all such sites in the developing world have joined together in a network called INDEPTH to make it easier to harmonize and strengthen methods, lower costs, and answer questions across multiple sites. ${ }^{15}$ There are presently 33 DSS sites in 14 countries in sub-Saharan Africa. However, there are many countries that have not yet attempted this approach, or are not yet using the data produced by sites to best advantage. There is growing experience in using DSS data for more accurate estimates of malaria specific mortality, and it has been claimed that DSS now represents for most of Africa, the single best potential source of data on cause-specific mortality within defined populations. ${ }^{6}$ Process indicators such as ITN or IPT coverage can also be tracked since household assets including ITNs are updated regularly and all pregnancies are registered. There remains a question regarding the degree to which results from small areas can be extrapolated to larger administrative areas for planning purposes, especially if these sites are also hosting mortality intervention trials or pilot health projects. Such questions need to be addressed through comparative studies; however, mortality rates in DSS sites tend to be comparable or worse than those seen in national averages from DHS surveys, perhaps because DSS sites tend to be placed in disadvantaged areas. ${ }^{15}$

Nationally representative, cross-sectional, retrospective surveys repeated every 4-8 years have much better continental coverage. More than 34 sub-Saharan African countries have had at least one DHS, and some have had as many as four, while 20 countries have had at least one MICS. The newest generation of DHS now includes extensive malaria modules with no fewer than 50 questions specifically on malaria (Eckert E, unpublished data). These have been applied in more than 10 DHS surveys so far and provide a wealth of population-based geo-coded data on illness episodes, health care, treatment-seeking behavior, use of ITNs, source and use of antimalarials, etc., all in addition to direct retrospective estimates of all-cause (but not cause specific) under-five mortality. Work is still needed to see if this enriched data set will be useful in estimating malaria-attributable mortality as well. A current limitation of DHS is that their frequency, every five years or so, is limited, making them less sensitive to rapid changes in coverage and impact. This is compounded by their retrospective nature, which means that their estimates of mortality are lagged to periods a few years prior to the year of the survey with an associated recall bias. The DHS surveys, for logistical reasons, are often done during dry seasons when fever frequency and malaria incidence are lower, and this might underestimate fever burdens, intervention coverages, and malaria preventive behaviors. Due to sample size, DHS estimates are relevant for relatively large areas and are not frequently used by decentralized district level planners. One unexplored frontier is to see how DSS and DHS/MICS could combine efforts strategically to harvest the complementarities from prospective and retrospective surveys. An initial way to examine this would be to conduct over-sampling of DHS or MICS surveys in areas where DSS is running and develop methods to extrapolate small area data to larger areas based on stratifications determined by DHS and MICS surveys as well as other sources such as census and nationally representative household budget surveys.

With the growing appreciation of the nexus of poverty and malaria, and the launch of major poverty alleviation initiatives, there is a timely and growing interest in equity analyses. ${ }^{16}$ Because data from the DSS, DHS, and MICS are linked at household level, powerful analyses can now be conducted, either in relatively small homogeneous areas as monitored in DSS sites, or across large disparate areas as covered by DHS and MICS. This has permitted household wealth ranking to be done on an enormous scale, and a new field of inquiry is opening that allows the monitoring of inequalities and inequities with regard to access to health interventions and to 
health outcomes. ${ }^{17-19}$ Equity analyses will be critical for understanding how interventions reach the poor, and for monitoring additional Millennium targets. Such work is not practically feasible with purely facility-based data. Abuja and MDGs for health are based on indicator targets from average population figures. It may be possible that on the road to meeting targets, disparities for the poorest actually increase (Gwatkin DR, unpublished data). It will be increasingly important to be concerned about not just the production of health, but also the distribution of health. Figures 3 and 4 show socioeconomic inequalities in access to health services and bed net ownership by wealth quintiles in a DSS in an apparently socioeconomically homogeneous rural area. $^{20}$

It is difficult to obtain comparable costing data for information systems. The DSS is often considered to be expensive; however, total cost for a full DSS site in Tanzania is approximately $\$ 3.50$ U.S. dollars per household per surveillance round or approximately $\$ 0.75$ per capita under surveillance per round. Since DSS sentinel data can be used for much larger populations beyond those in the sample, actual costs to the system are less than $\$ 0.02$ U.S. dollars per capita annually. On the same basis, the less frequent DHS also costs $\$ 0.02$ U.S. dollars per capita when spread annually, while the national health facility HMIS in Tanzania is estimated to cost $\$ 0.06$ per capita annually. ${ }^{21}$

\section{REMOTE SENSING AND MODELING}

A source of input data useful to malaria control can be obtained from routine remote sensing and modeling. ${ }^{22-26}$ Again, this can be deployed in a prospective or retrospective manner. On the prospective side, an experiment is underway that combines remote sensing data with real-time health facility data to provide, in a sequence of flags, forecasting, early warning, and early detection of malaria epidemics (Figure $5) .{ }^{27}$ This is an example of triangulation and integration of data of different types and from disparate sources into a system that could be highly cost-effective.

The increasing value of spatial and environmental information systems made possible by modern geographic informa- tion system (GIS) applications should not be overlooked. The Mapping Malaria Risk in Africa (MARA) collaboration exemplifies this effort. ${ }^{28}$ The malaria control community now uses MARA model maps and estimates widely. The MARA recently launched a new information product called MARA-LITe for Africa. It is a CD-ROM based tool that allows anyone with a computer to query a GIS model down to district level across Africa to get estimates of transmission risk based on climate models, and of population sub-groups at risk for any area selected, as well as a complete interactive mapping interface (www.mara.org.za/maralite.htm). This is a potentially useful tool for National Malaria Control Programs and District level planners prior to monitoring and evaluation in the evidence-based pathway. Another important vehicle for assisting the mapping of malaria control and related process indicators at national and sub-national level is the WHO HealthMapper, a free, easy to use, yet powerful data management and mapping tool that has already been used by regional and national malaria control programs, and may prove useful to district health managers for mapping their HMIS process indicators and packaging evidence (e.g., coverage of ITNs). (http://www.who.int/csr/mapping/tools/ healthmapper/healthmapper/en).

A general observation that is emerging is that HMIS, DSS, and Epidemic Early Detection Systems can be applied in the form of sentinel systems. Where quality data are too costly to collect everywhere, strategically located sentinel health facilities or population areas from which results can be generalized to larger areas or populations can be highly cost-effective. Planners and stakeholders are now using sentinel surveillance for monitoring antimalarial drug resistance, burden of disease profiles, and for poverty indicators. Although data from the immediate local area are always wanted, perhaps in many cases it is only data from a representative sentinel that is actually needed: an example of Finagle's Second Law. It is clear from Table 2 that no single source can supply all the impact and process indicators that are necessary for monitoring progress and impact of malaria control. This means that the HMIS needs to embrace and use these other sources in a more integrated fashion, and move towards a true systems approach that builds on synergies among the sources.

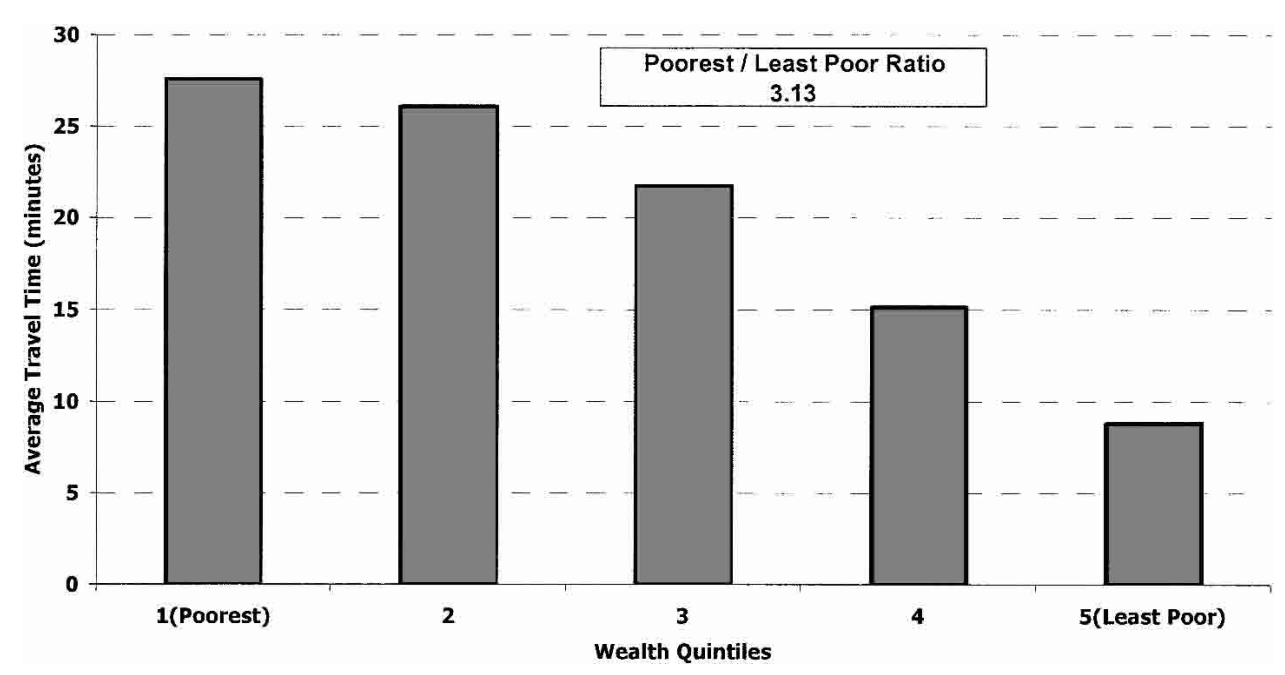

FigurE 3. Average travel time from household to nearest health facility for 13,000 households in a rural area of Tanzania, by household wealth quintiles. TEHIP = Tanzania Essential Health Intervention Project. Source: TEHIP Rufiji Demographic Surveillance System. 


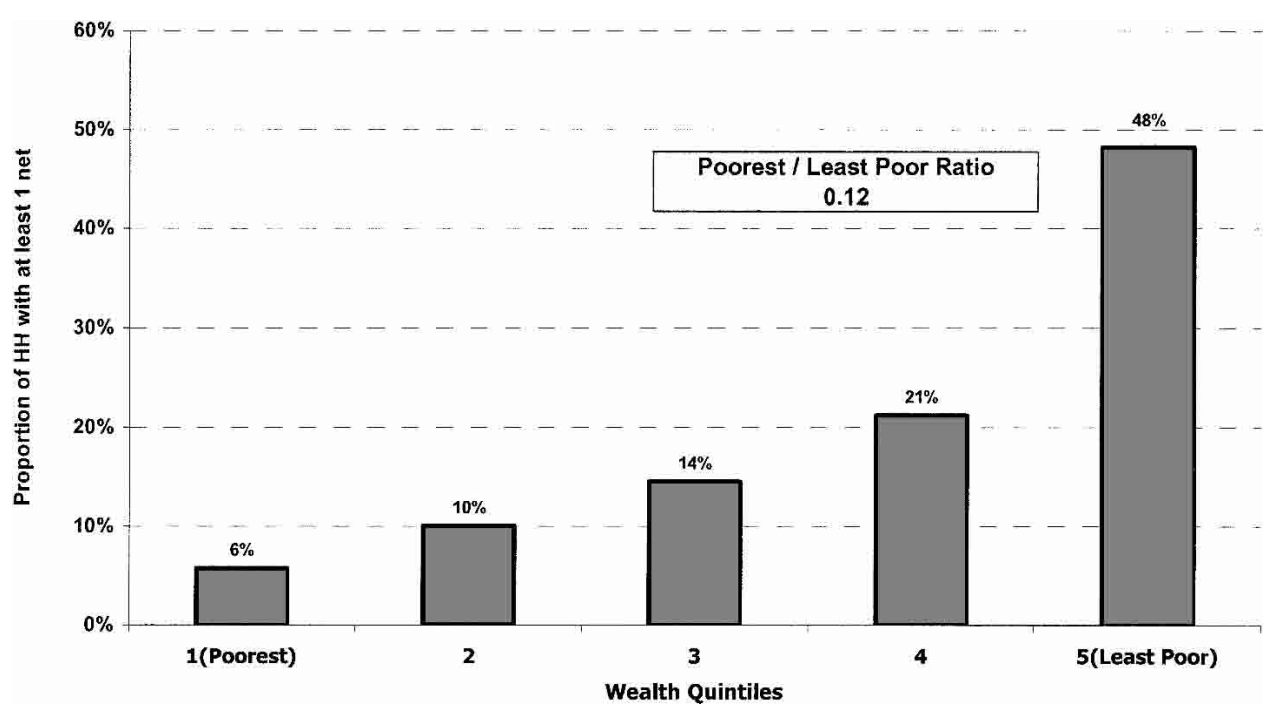

FIGURE 4. Bed net ownership at the beginning of a social marketing program in 13,000 households in a rural area of coastal Tanzania, by household wealth quintiles. TEHIP = Tanzania Essential Health Intervention Project. Source: TEHIP Rufiji Demographic Surveillance System.

\section{CONCLUSIONS}

In recent years, there have been many energetic attempts to strengthen facility-based health information systems. However, this investment will not help monitor the more important population-based impact and process indicators. The HMIS needs radical reform to become more relevant to managers, to catch up to the new reality of syndromic diagnoses, and to justify its current expense. It needs to evolve to a more coherent and integrated health information system that can serve local, national, and global needs. The most promising source of data for specific impact measures, the DSS, has shown virtually no growth or new investment. There have been only a few new DSS sites established, and these were in countries that already had multiple sites and were aware of

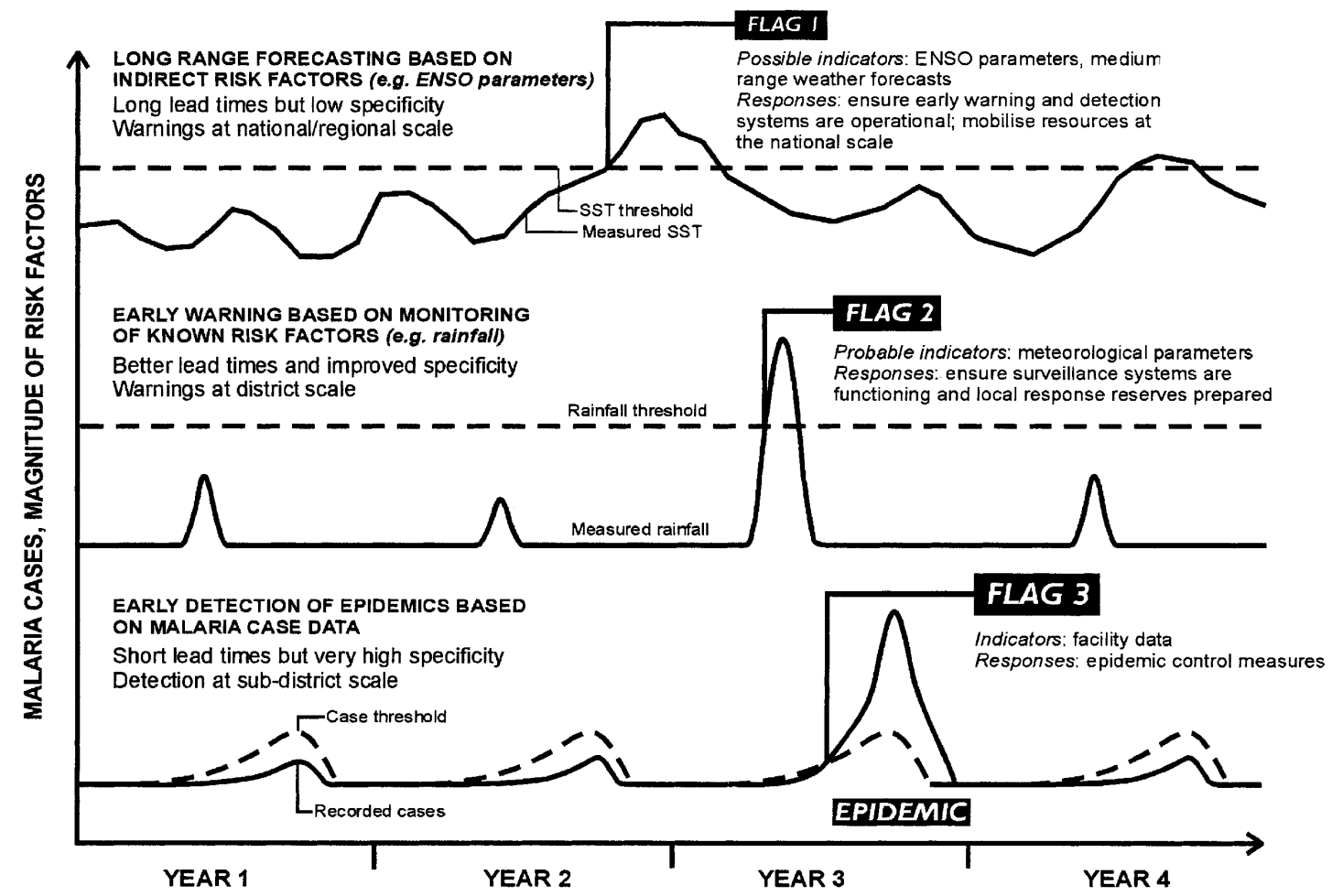

FIGURE 5. A three-tiered approach for long-range forecasting, early warning, and early detection of malaria epidemics. Each tier is associated with specific indicators and responses. In this example, Flag 1 is raised at the regional level when sea-surface temperature anomalies signal an impending El Niño event. Subsequent rainfall is monitored directly as part of an early warning system and Flag 2 is raised if it is in excess. Malaria cases are monitored at local health facilities and an epidemic is quickly declared once a defined threshold is exceeded (Flag 3 ) and the other flags are up. ENSO = El Niño Southern Oscillation. Source: Cox and others. ${ }^{27}$ 
TABLE 2

Availability of selected malaria control indicators in main potential data sources*

\begin{tabular}{|c|c|c|c|c|c|c|}
\hline \multicolumn{7}{|c|}{ Potential data sources for malaria control } \\
\hline Common malaria control indicators & HMIS & HFS & DHS & MICS & DSS & $\mathrm{RS}$ \\
\hline \multicolumn{7}{|l|}{ Impact } \\
\hline All-cause under 5 mortality in population & & & - & - & - & \\
\hline Malaria-attributed mortality in population & & & & & $\bullet$ & \\
\hline Malaria as \% of outpatient visits & - & - & & & & \\
\hline Malaria as $\%$ of inpatient admissions & - & - & & & & \\
\hline Malaria as \% of hospital deaths & - & - & & & & \\
\hline \multicolumn{7}{|l|}{ ITNs } \\
\hline Household possession of nets/ITNs & & & • & & • & \\
\hline$\%$ of children less than five years old sleeping under net/ITN & & & • & • & - & \\
\hline \multicolumn{7}{|l|}{ Antimalarial treatment } \\
\hline$\%$ of febrile children less than five years old treated with antimalarial & & & $\bullet$ & $\bullet$ & & \\
\hline$\%$ of diagnosed clinical cases correctly managed & & • & & & & \\
\hline Drugs out of stock in clinics & - & • & & & & \\
\hline \multicolumn{7}{|l|}{ Antimalarial treatment } \\
\hline$\%$ of pregnant women attending ANC & & & • & • & - & \\
\hline$\%$ of pregnant women taking IPT & & & - & & - & \\
\hline$\%$ of pregnant women sleeping under net/ITN & & & $\bullet$ & & $\bullet$ & \\
\hline Epidemic response & - & & & & & $\bullet$ \\
\hline
\end{tabular}

* Adapted and modified from the World Health Organization United Nations Children's Fund Africa Malaria Report 2003. ${ }^{12}$ HMIS $=$ Health Management Information System; HFS $=$ Health Facility Survey; DHS = Demographic and Health Survey; MICS = Multi-indicator Cluster Survey; DSS = Demographic Surveillance System; RS = Remote Sensing and Modeling; ITNS = insectide-treated mosquito nets; ANC = antenatal care; IPT = intermittent presumptive treatment.

their value. A goal of having each malarious country with at least one rural and one urban sentinel DSS capability used in evidence-based planning as part of an integrated Health Information System is financially and operationally feasible, but still not happening. Finagle's third law still applies. The data we need are not available in such countries. But on a positive note, there have been major increases in the number of countries with DHS and MICS surveys that now include relevant malaria indicators. This could prove invaluable, but DHS and MICs style surveys would need to be implemented much more frequently to be useful to monitor impact of malaria control. Coupling DHS, MICS, and DSS in innovative ways could provide a practical means to measure impact.

The RBM as a movement was always intended to be a pathfinder. Given the magnitude of malaria as a problem for Africa, RBM with WHO are moving into the forefront in advocating for, and developing integrated management information systems for core health and poverty indicators. Resources for such systems are still sorely lacking. A wake-up call is needed to bring new resources on board, and to reallocate some existing HMIS resources to the more appropriate integrated information systems that are able to document allcause and cause-specific mortality, track health seeking process indicators, and monitor poverty reduction indicators. Our best hope to get the data we need for mortality impact in the near term may be a strategic combination of the sentinel DSS and national DHS household survey systems at country level feeding into a strengthened backbone of a sector-wide, or even inter-sectoral management information system.

Received August 21, 2003. Accepted for publication January 14, 2004.

Acknowledgment: The paper is based on an invited presentation by Don de Savigny at the Third Multilateral Initiative on Malaria, PanAfrican Conference, Arusha, Tanzania, November 2002.

Disclosure: Fred Binka is the Executive Director of the INDEPTH network.

Authors' addresses: Don de Savigny, Swiss Tropical Institute, Box
4002, Basel, Switzerland, Telephone: 41-61-284-8221, Fax: 41-61-2717951, E-mail: d.desavigny@unibas.ch. Fred Binka, INDEPTH Network, 9 Adenkum Loop, Kanda, Box 14550, Accra, Ghana, Telephone: 233-21-254-752, Fax: 233-21-254-755, E-mail: indepth@ africaonline.com.gh.

\section{REFERENCES}

1. Millennium Assembly of the United Nations, 2000. Millennium Development Goals. http://www.un.org/millenniumgoals/.

2. Nabarro D, Tayler E, 1998. The "roll back malaria" campaign. Science 280: 2067-2068.

3. World Health Organization, 2000. The African Summit on Roll Back Malaria. Geneva: World Health Organization. (WHO/ CDS/RBM/2000.17).

4. Delaunay V, Etard JF, Preziosi MP, Marra A, Simondon F, 2001. Decline of infant and child mortality rates in rural Senegal over a 37-year period (1963-1999). Int J Epidemiol 30: 12861293.

5. UNICEF, 2001. http://www.unicef.org/specialsession/about/ sgreport-pdf/01_InfantAndUnder-FiveMortality_D7341Insert_ English.pdf. Accessed January 9, 2004.

6. Korenromp EL, Williams BG, Gouws E, Dye C, Snow RW, 2003. Measurement of trends in childhood malaria mortality in Africa: an assessment of progress toward targets based on verbal autopsy. Lancet Infect Dis 3: 349-358.

7. Sachs J, Malaney P, 2002. The economic and social burden of malaria. Nature 415: 680-685.

8. Lengeler C, 2000. Insecticide treated nets and curtains for preventing malaria. Cochrane Database Syst Rev 320.

9. Schellenberg D, Menendez C, Kahigwa E, Aponte J, Vidal J, Tanner M, Mshinda H, Alonso P, 2001. Intermittent treatment for malaria and anaemia control at time of routine vaccinations in Tanzanian infants: a randomised, placebo-controlled trial. Lancet 357: 1471-1477.

10. Tanzania IMCI multi-country evaluation health facility survey study group, 2004. Health care for under-fives in rural Tanzania: effect of integrated management of childhood illness on observed quality of care. Health Policy Plan 19: 1-10.

11. World Bank, 2002. World Bank Estimates Cost of Reaching Millennium Development Goals at \$40-60 Billion Annually in Additional Aid. Washington, DC: World Bank Press Release No.2002/212/5. 2002.

12. WHO, UNICEF, 2003. The Africa Malaria Report 2003. Geneva: 
World Health Organization. Rep. WHO/CDS/MAL/ 2003.1093.

13. WHO, 2000. Roll Back Malaria Framework for Monitoring Progress and Evaluating Outcomes and Impact. Geneva: World Health Organization. WHO/CDS/2000.25.

14. Remme JH, Binka F, Nabarro D, 2001. Toward a framework and indicators for monitoring Roll Back Malaria. Am J Trop Med Hyg 64: 76-84.

15. INDEPTH, 2001. INDEPTH Monograph Series: Demographic Surveillance Systems for Assessing Populations and their Health in Developing Countries. Volume 1: Population, Health and Survival in INDEPTH Sites. Ottawa: International Development Research Centre.

16. Gwatkin DR, 2003. How well do health programmes reach the poor? Lancet 361: 540-541.

17. Wagstaff A, 2000. Socioeconomic inequalities in child mortality: comparisons across nine developing countries. Bull World Health Organ 78: 19-29.

18. Gwatkin DR, Rustein S, Johnson K, Pande R, Wagstaff A, 2000. Tanzania: Socio-Economic Differences in Health, Nutrition, and Population. Washington, DC: World Bank's Health and Population Advisory Service.

19. Woelk G, Chikuse P, 2000. Using Demographic and Health Survey (DHS) Data to Describe Intra Country Inequities in Health Status: Zimbabwe. Harare, Zimbabwe: Social Science and Medicine Africa Network (SOMANET), University of Zimbabwe.

20. Mwageni E, Masanja H, Momburi D, Mkilindi Y, Mbuya C, Kasale H, Reid G, de Savigny D, 2002. Health Seeking Behaviour in Severe Malaria in Rural Tanzania. Multilateral Initiative on Malaria. Third Multilateral Initiative on Malaria PanAfrican Malaria Conference, Arusha, Tanzania, 2002.

21. Rommelmann V, Setel P, Hemed Y, Mponezya H, Angeles G, Boerma T, 2003. Costs and results of information systems in Tanzania: descriptions of indicator coverage and systems with preliminary comparative costings. Measure Evaluation. Chapel Hill, NC: University of North Carolina Press.

22. Connor SJ, Thomson MC, Flasse SP, Perryman AH, 1998. Environmental information systems in malaria risk mapping and epidemic forecasting. Disasters 22: 39-56.

23. Hay SI, Simba M, Busolo M, Noor AM, Guyatt HL, Ochola SA, Snow RW, 2002. Defining and detecting malaria epidemics in the highlands of western Kenya. Emerg Infect Dis 8: 555-562.

24. Rogers DJ, Randolph SH, Snow RW, Hay SI, 2002. Satellite imagery in the study and forecast of malaria. Nature 415: 710 715.

25. Hay SI, Rogers DJ, Shanks D, Snow RW, Myers MF, Snow RW, 2001. Malaria early warning in Kenya. Trends Parasitol 17: 95-99.

26. Snow RW, Hay SI, Rogers DJ, Noor AM, Omumbo JA, Ochola S, 2000. Developing a Multi-Sensor Satellite Imagery Based Planning Tool for Malaria Control in Africa: Putting Research into Practice in Kenya. Nairobi, Kenya: Kenya Medical Research Institute and Oxford, United Kingdom: University of Oxford.

27. Cox J, Craig M, Le Sueur D, Sharp B, 1999. Mapping Malaria Risk in the Highlands of Africa. London and Durban, South Africa: HIMAL/MARA.

28. Snow RW, Marsh K, Le Sueur D, 1996. The need for maps of transmission intensity to guide malaria control in Africa. Parasitol Today 12: 455-457. 